\title{
The Relationship between Institutional Environment and Enterprise's Technology Innovation Performance-The Visual Angle Based on MOA Theoretical Model
}

\author{
Shuying Wang ${ }^{1}$ and Xingye Xiao ${ }^{1}$ \\ ${ }^{1}$ School of Management Engineering, Zhengzhou University, Zhengzhou 450001, China \\ Email: wangshuying@zzu.edu.cn, 408640203@qq.com
}

\begin{abstract}
This paper discusses the relationship between institutional environment and technological innovation performance from the perspective of MOA, and analyzes the moderating role of external social capital and top management team heterogeneity in the relationship between institutional environment and technological innovation performance. It is found that good institutional environment can improve the performance of technological innovation significantly; social capital as an informal, non-mandatory system to regulate individual behavior and promote the company's technological innovation performance; senior management team heterogeneity and technological innovation significantly Negative correlation. Finally, it discusses the management revelation of the conclusion and gives some policy suggestions.
\end{abstract}

Keywords. Institutional environment, technological innovation performance, executive team heterogeneity, corporate social capital.

\section{Introduction}

Technological innovation is the root of the enterprise to obtain and maintain the core competitive advantage. However, with the intensification of market competition, the increase of economic environment uncertainty and the rapid development of knowledge economy, China's enterprise technology innovation is faced with unprecedented challenges and enormous pressure. From the practical level, the total R\&D investment in China's total industrial added value accounted for only $1.9 \%$, with the United States, Germany, South Korea, 28 countries and Japan and other advanced developed countries a far cry, indicating that China's R\&D Low, a serious shortage of technological innovation capacity [1]. From a theoretical point of view, technological innovation is the enterprise in order to seek profit maximization, to reduce the external suppression of technology caused by self-defense behavior taken [2]. The existing literature on the enterprise network capabilities, financial development, internal and external control and other aspects of the impact of technological innovation of enterprises [3]. However, there are few literatures on the internal influence of external environment on the performance of technological innovation, especially from the perspective of institutional environment to study the relationship between technological innovation. Specifically, how does the institutional environment affect the technological innovation of enterprises is still a "black box" that 
has not been opened yet, and whether the improvement of regional institutional environment can enhance the performance of technological innovation? Does the heterogeneity of internal competencies (externalities) and external opportunities (corporate social capital) of firms have an innovative heterogeneity in response to regional institutional environments? The answers to these questions have important theoretical value and practical significance to promote the development of technological innovation of listed companies and to solve the effective integration of resources [4].

Based on the MOA theory, this paper integrates the regional institutional environment, corporate social capital and executive team heterogeneity into a unified analytical framework. By analyzing the impact of institutional environment on the technological innovation performance of enterprises, (Heterogeneity of senior management team) and the external environment (social capital) to try to provide the theoretical interpretation and empirical answer for the above-mentioned problems. Firstly, based on the concept of resource integration, the innovation performance of enterprises is regarded as the common result of power, opportunity and ability. The integration of theoretical model and the effect of technological innovation performance on enterprise's technological innovation performance is discussed in this paper. Factors of the empirical analysis. Second, in the study of "high-level echelon theory", empirical research on corporate executives and technological innovation capacity is rare. This paper uses listed companies as research samples, and increases the diversity of the literature. Thirdly, the enterprise scale, the enterprise age and the net profit are taken as the control variables, and the impact of the institutional environment on the enterprise's technological innovation performance is studied, which enriches the enterprise innovation literature research.

\section{Theory and hypotheses}

MOA theory points out that only having the motive, opportunity, and ability elements at the same time is a necessary condition for producing certain results. As the institutional environment on the enterprise $R \& D$ investment have a direct impact on enterprises to enhance technological innovation performance of the "motives" [5]; as the executive team of innovation-oriented, innovative decision-making and innovative resource integration irreplaceable role, thus affecting innovation performance Social capital is the key "opportunity" for technological innovation of enterprises because of the important support for the grasp of technological innovation opportunities by corporate social capital. Based on the above analysis, this paper proposes the following hypotheses on the basis of the MOA theory: institutional environment, executive team heterogeneity and social capital.

\subsection{Institutional environment and technological innovation performance of enterprises}

The innovation literature generally argues that when faced with increasing external uncertainties, firms tend to pursue more advanced and competitive innovation strategies to protect their market position [6]. Xu, Wenjun and Feng Tao (2016) pointed out that the improvement of the institutional environment can significantly increase the total amount of capital allocation and the duration of allocation of technological innovation projects to promote technological innovation [7]; Liu Jibing, Wang Qi and Ma Huanyu 2015) pointed out that the regional policy environment and market environment for enterprise innovation ability has a significant positive impact, and thus promote the technological innovation performance [8]. Liao Kairong and Chen Shuangying (2011) take the national private enterprise survey data in 2006 as a sample to analyze the impact of external institutional environment on the R\&D investment of private enterprises [9]. The research shows that a good external institutional environment will promote R\&D investment of private enterprises, (2011) study shows that the institutional context deeply affects the enterprise's R\&D expenditure behavior [10]; Rainder (2012) found that the competitive market environment in the (2016) analyzed the impact of institutional environment on the performance of technological innovation in 266 enterprises in two traditional industrial clusters in Zhejiang province [11]. The results show that the efficiency of 
technological innovation is higher and the innovation efficiency is faster. Found that there is a significant role between the two [12]. Therefore, based on the above analysis, this paper proposes the following assumptions:

H1: Good institutional environment is promoting enterprise technological innovation.

\subsection{Top management team heterogeneity and enterprise technology innovation performance}

Team heterogeneity refers to the differences in the demographic characteristics of team members as well as important cognitive concepts, values, and experience [13]. Specific to the heterogeneity of executive team, including the level of education, entrepreneurial experience and other easy to observe the external heterogeneity and cognition, values, preferences, attitudes, entrepreneurial commitment and other deep internal heterogeneity [14]. The echelon theory points out that the different cognitive bases, values, insights, and processes that influence the strategic choice and organizational performance of the organization's members [15]. As the leader of strategic decision-making, the top management team influences their behavior by their cognition and values, and maximizes the role of senior management team in strategic choice and development direction. However, with the extension of executive tenure, corporate strategy will be the lack of change, easy to fall into the rigid corporate governance model, which will not conducive to enterprise management. In other words, with the growth of executive tenure, senior management team easy to produce too much self-confidence, resulting in management thinking and behavior may be sticky, resulting in decreased technological innovation output. Based on this, this paper, senior management team heterogeneity of the term of senior management team heterogeneity on the impact of technological innovation performance.

O.Relly \& Flatt (1989) argue that, in the enterprise life cycle, enterprise innovation and senior management team heterogeneity is negatively correlated [16]; Ma Fuping and Guo Xiaochuan (2010) pointed out that executive team heterogeneity of technological innovation 2006 to 2010 China's small and medium-sized enterprises listed companies as a sample of the empirical study of entrepreneurial enterprise executive team heterogeneity of the direct impact of entrepreneurship-oriented research [17], the study has a positive impact on the performance of China's A-share listed companies in manufacturing research shows that the heterogeneity of executive team R\&D investment from the negative phase of [18, 19]; the same time, Chen Rui (2005) take the data samples of listed companies in Fujian Province and Shandong Province as an example, the results show that the higher the team heterogeneity, the greater the investment in technological innovation [20]; Bai Jingkun And Li Sha-sha (2015) show that there is a significant negative correlation between executive team heterogeneity and innovation performance [21]; Lei Hui and Liu Peng (2013) take the listed companies of China's SME sector as the research object, This indicates that executive team heterogeneity is significantly negatively correlated with technological innovation [22]. Therefore, based on the above analysis, this paper proposes the following assumptions:

$\mathrm{H} 2$ : There is a negative correlation between executive team heterogeneity and enterprise technological innovation performance.

\subsection{Social capital and enterprise technology innovation performance}

Putnam (2014) argues that social capital refers to trust, norms, and networks that can improve social efficiency through coordinated action, and thus social capital is embodied in mutual trust, civic awareness, and mutual benefit. It has created a good interactive environment for enterprise technological innovation and economic and talent exchange [23]. Social capital includes social trust, social organization, social participation and so on. As an institutional framework, social capital has created a policy and institutional environment foundation for enterprise technological innovation, which provides an opportunity for the improvement of technological innovation performance $[24,25]$.

On the one hand, a good external social capital, to promote internal mechanisms to play a role. In other words, external social capital through the enterprise's innovation power, innovation process and innovation results in three 
aspects to influence the enterprise's innovation ability. Cheng Cong and Xie Hongming (2012) pointed out that social capital is one of the key factors to determine whether enterprises can obtain the performance of technological innovation. On the other hand, social capital can promote technological innovation by using external resources and knowledge integration. Zhang Honghui (2014) pointed out that in the R\&D activities, social capital can promote the sharing of knowledge, and thus has a fundamental decision on technical activities [26]. Capello \& Faggian (2005) argues that the exchange of R\&D activities and knowledge is synchronized, and the network of individual interactions of social capital increases the trust between people and strengthens communication between individuals. Type "link ties. Such weak ties are a useful complement to the success of R\&D activities for strong ties such as 'family'. Therefore, based on the above analysis, this paper proposes the following hypothesis:

H3: Social capital is promoting enterprise technology innovation performance.

\section{Research design}

\subsection{Sample selection and data sources}

The paper chooses the data of A-share listed companies in 61 high-tech industries (communication equipment, software development, semiconductors and electrical equipment) in Shanghai and Shenzhen in 2009-2015 as the samples, and makes a comparative study on the relationship between institutional environment and technological innovation performance:(1) Try to choose more frequent R\&D activities of high-tech industry listed companies; (2) To exclude listed companies that have been or are being used by ST, ST, SST, S*ST and S; (3) Elimination of missing data of listed companies, the final sample of 61 listed companies. Due to limited space, not a detailed list of the specific list of sample companies. The original data of this article is listed company's annual report and listed company information disclosed on the website of Shanghai Stock Exchange and Shenzhen Stock Exchange.

\subsection{Variable measurement}

Dependent variable: enterprise technology innovation performance. Most of the variables in the literature measure technological innovation activities are divided into two categories: one is the input, that is, investment in R\&D, R\&D personnel input; the second is output, that is, the number of patents, new products, new Product sales. In view of the reliability and availability of data, this paper draws lessons from Liu Yun-guo and Liu Wen (2007), because of the low number of new products and the comparability of data in China's annual reports, and the sales income index is easy to be "manipulated by earnings" [27].The ratio of R\&D expenditure to the total assets at the end of the period is taken as the proxy variable of the enterprise's technological innovation performance [28].

Independent variables: institutional environment, executive team heterogeneity, and social capital. The Institutional Environment Indicator (Evm) of the paper is also based on the China Business Environment Index for 2013 published by Wang Xiaolu, Yu Jingwen and Fan Gang (2013) [29]. In this report, the operating environment index has the data of seven years from 2009 to 2015, according to the data of the seven-year average, the average higher than the national average of the sample into the "institutional environment better" group; Into the "institutional environment is poor" group, the system environment is better assigned a value of 1 , or 0 . Institutional environment indicator is a comprehensive index, including the level of marketization, the level of government governance, the level of the legal system and so on. Executive team heterogeneity, senior management team performance for the rich cognitive, management, interest and experience in the accumulation process. The heterogeneity of tenure has two sides to the enterprise's technological innovation performance, which provides a good opportunity window for observing the heterogeneity of the executive team. Therefore, this paper draws on $\mathrm{Hu}$ Wangbin, Zhang Yuli and Yang Jun (2014) to study the heterogeneity of senior management team by the tenure heterogeneity (the ratio of the standard deviation of the senior management age and the average value). Social capital, from the relevant research literature on the "social capital" of the definition and measurement methods, this 
paper from the number of regional social organizations, the natural logarithm of the measurement of regional social development, social capital data from the "China City Commercial Credit Environmental Index official website" and China Statistical Yearbook for the years 2009-2015.

Control variables: In order to control the impact of other factors on the research model, this paper select the enterprise size, corporate net profit, corporate age as a control variable.

Table 1. Variable definitions and variable design.

\begin{tabular}{|c|c|c|c|}
\hline The type of the variable & The variable name & $\begin{array}{l}\text { Variable } \\
\text { symbol }\end{array}$ & Variable definition \\
\hline Explained variable & $\begin{array}{c}\text { Technological } \\
\text { Innovation Performance }\end{array}$ & $\mathrm{RD}$ & $\mathrm{R} \& \mathrm{D}$ investment / total assets \\
\hline \multirow{3}{*}{ Explanatory variables } & $\begin{array}{l}\text { Executive Team } \\
\text { Heterogeneity }\end{array}$ & MH & $\begin{array}{c}\text { Executive Team age standard } \\
\text { deviation / age mean }\end{array}$ \\
\hline & Social capital & $\mathrm{SC}$ & $\begin{array}{c}\text { The natural logarithm of social } \\
\text { organization }\end{array}$ \\
\hline & $\begin{array}{l}\text { Institutional } \\
\text { environment }\end{array}$ & INDEX & $\begin{array}{c}\text { System environment is good } 1, \\
\text { otherwise } 0\end{array}$ \\
\hline \multirow{3}{*}{ Control variables } & Enterprise size & SIZE & $\begin{array}{l}\text { The natural logarithm of the } \\
\text { number of employees in an } \\
\text { enterprise }\end{array}$ \\
\hline & Business age & AGE & $\begin{array}{c}\text { Based on } 2009, \text { there are } 7 \\
\text { dummy variables }\end{array}$ \\
\hline & Net profit & $\mathrm{P}$ & $\begin{array}{l}\text { The natural logarithm of the net } \\
\text { profit of the enterprise at the end } \\
\text { of the year }\end{array}$ \\
\hline
\end{tabular}

\subsection{Descriptive statistical analysis}

Table 2 shows the descriptive statistics of the main variables. From the sample company's technical innovation indicators (exp) point of view, the mean value is 0.03 and the standard deviation is 0.05 , which indicates that the technological innovation activity of listed companies in our country is weak, and there are big differences among the companies; The mean value of executive team heterogeneity $(\mathrm{mh})$ is 0.17 and the standard deviation is 0.04 , which indicates that there is a big difference in executive team; The maximum of social capital (sc) is 11.18 , the minimum is 7.77 , and the standard deviation is 0.68 , which shows that there is significant difference in the social capital of each region; The maximum value of the system index is 1.00 , the minimum value is 0.00 and the standard deviation is 0.48 , which indicates that the development of institutional environment is not balanced in our country at present.

Table 2. Variable descriptive statistics.

\begin{tabular}{|c|c|c|c|c|}
\hline & RD & MH & SC & INDEX \\
\hline Mean & 0.03 & 0.17 & 9.82 & 0.34 \\
\hline Median & 0.02 & 0.17 & 9.91 & 0.00 \\
\hline Maximum & 0.47 & 0.29 & 11.18 & 1.00 \\
\hline Minimum & 0.00 & 0.04 & 7.77 & 0.00 \\
\hline Std. Dev. & 0.05 & 0.04 & 0.68 & 0.48 \\
\hline Skewness & 4.97 & 0.04 & -0.60 & 0.66 \\
\hline Kurtosis & 34.58 & 2.83 & 3.06 & 1.43 \\
\hline Jarque-Bera & 19503.95 & 0.62 & 25.54 & 74.45 \\
\hline Probability & 0.00 & 0.74 & 0.00 & 0.00 \\
\hline Sum & 14.09 & 73.05 & 4192.30 & 147.00 \\
\hline Sum Sq. Dev. & 0.91 & 0.72 & 198.85 & 96.39 \\
\hline
\end{tabular}




\subsection{Research design}

Based on the research questions and the research variables, this paper constructs an empirical analysis model of institutional environment and technological innovation performance.

$$
E X P_{i t}=\beta_{0}+\beta_{1} M H_{i t}+\beta_{2} S C_{i t}+\beta_{3} \text { Index }_{i t}+\sum_{i=7}^{n} \beta_{i} C O N_{i t}+\varepsilon_{i t} E X P_{i t} \text { indicates the Technological Innovation Performance }
$$

of Enterprise $\mathrm{i}$ in $\mathrm{t}$ year; $M H_{i t}$ indicates the Executive Team Heterogeneity of Enterprise i in $\mathrm{t}$ year; $S C_{i t}$ indicates the Social capital of Enterprise $\mathrm{i}$ in $\mathrm{t}$ year; Index ${ }_{i t}$ indicates the Institutional environment of Enterprise $\mathrm{i}$ in t year; $C O N_{i t}$ indicates the Control variable set; $\varepsilon_{i t}$ indicates the Random error term.

\section{Result and analyze}

\subsection{Regression analysis}

First of all, this data belongs to the panel data, reducing the time series of multi-collinearity problem, so the first to determine whether the time series is stationary, and the existence of "pseudo-regression" phenomenon. A unit root test using Eviews 7.2 yields the following results (Table 3):

Table 3. Unit Root Test of Variables.

\begin{tabular}{|c|c|c|}
\hline Method & Statistic & Prob.** \\
\hline Im,Pesaran and Shin W-stat & -11.44 & 0.00 \\
\hline ADF-Fisher Chi-square & 1277.39 & 0.00 \\
\hline PP-Fisher Chi-square & 1669.25 & 0.00 \\
\hline
\end{tabular}

As can be seen from Table 3, the selected data is stable. Following the use of cointegration test, test whether there is a "pseudo-regression" equation, as shown in Table 4:

Table 4. Co-integration test of variables.

\begin{tabular}{|c|c|c|c|c|}
\hline Variable & Coefficient & Std. Erro & t-Statistic & Prob. \\
\hline RESID?(-1) & -1.34 & 0.09 & -13.90 & 0.00 \\
\hline D(RESID?(-1)) & 0.16 & 0.06 & 2.38 & 0.01 \\
\hline
\end{tabular}

As can be seen from Table 4, at 5\% significant level to reject the null hypothesis through the KOA test. Thus, there is a cointegration relationship between institutional environment, social capital, and executive team heterogeneity in panel data on the performance of technological innovation.

Secondly, the F-test and the T-test are used to test the fixed effect and the random effect. The test results reject the null hypothesis, indicating that the fixed effect and the random effect are the significant influencing factors in the model. Thirdly, according to the Hausman test, the model is set, and the result shows that the fixed effect should be used in the static panel data model. Limited by space, the specific regression analysis did not give a report. 
According to the fixed-effect regression results, it can be seen that the index coefficient of the system is 0.01 and is significant at the level of $5 \%$, the results show that the institutional environment is positively related to the performance of technological innovation. In other words, the more perfect the institutional environment, the easier the technological innovation and the higher the innovation performance. The coefficient of external social capital (sc) is 0.01 , and is significant at the level of $5 \%$, the results show that there is a positive correlation between external social capital and technological innovation performance. In other words, the more abundant external social capital is, the easier it is for technological innovation and the higher the technological innovation performance. The coefficient of heterogeneity $(\mathrm{mh})$ for the top management team is -0.17 and is significant at the $5 \%$ level, the results show that there is a negative correlation between executive team heterogeneity and enterprise technological innovation performance. In other words, with the growth of senior management, senior management team is easy to produce too much self-confidence, resulting in management thinking and behavior may be sticky, resulting in decreased technological innovation output, technological innovation performance of listed companies decreased.

Table 5. Fixed effect regression results.

\begin{tabular}{|c|c|c|c|c|}
\hline Variable & Coefficient & Std. Error & t-Statistic & Prob. \\
\hline $\mathrm{C}$ & -0.07 & 0.04 & -1.74 & 0.08 \\
\hline $\mathrm{MH}$ & -0.17 & 0.06 & -3.11 & 0.00 \\
\hline $\mathrm{SC}$ & 0.01 & 0.00 & 3.20 & 0.00 \\
\hline $\mathrm{INDEX}$ & 0.02 & 0.01 & 3.39 & 0.00 \\
\hline $\mathrm{AGE}$ & -0.00 & 0.00 & -4.32 & 0.00 \\
\hline $\mathrm{SIZE}$ & 0.01 & 0.00 & 2.06 & 0.04 \\
\hline $\mathrm{P}$ & 0.00 & 0.00 & 0.24 & 0.81 \\
\hline
\end{tabular}

\section{Discussion and conclusion}

Today's domestic and foreign economic situation is so grim, in addition to some large or state-owned enterprises, most of the enterprise development is difficult, its survival and growth faces enormous challenges, and only continue to carry out technological innovation activities, access to and build the core competitiveness of enterprises is imperative. Based on the data of A-share listed companies in Shanghai and Shenzhen stock markets, this paper constructs the relationship model between corporate social capital, institutional environment, executive team heterogeneity and technological innovation performance. Through empirical research, the following conclusions are drawn: First, corporate social capital, institutional environment, technological innovation performance of enterprises has a significant impact, but there are differences in the impact factor. The influence degree is the institutional environment, social capital from high to low respectively; Second, the improvement of China's regional institutional environment is more conducive to improving the level of technological innovation performance of private listed companies; social capital can have a positive stimulating effect on corporate R \& D investment, corporate social capital is conducive to the improvement of technological innovation performance ; Thirdly, in the listed companies, the heterogeneity of senior management team has negative effect on the performance of technological innovation. The higher the senior team is, the longer the term is, the more unfavorable for enterprise technological innovation.

In the process of enterprise development, often due to the lack of effective support of the organizational structure of the inter-enterprise technical interruption caused by enterprises to improve the level of technological innovation, by adjusting the senior management of gender, age, education, professional background, functional background and 
Education background and functional background heterogeneity, choose more young, highly educated, science and engineering background, engaged in output-type functional background of senior management staff to makes the team heterogeneity level is low. For the listed companies, through external social capital can obtain more technological innovation resources, enterprises can effectively strengthen the external network through organizational change, in order to better learn new knowledge, new experience, and effectively promote the enterprises to achieve technological innovation.

Based on the above analysis, this paper proposes the following policy recommendations:

First, optimize the regional policy and institutional environment, expand diversified government support channels. The government should broaden the channels of support, in addition to giving certain tax incentives and support funds, but also to build a better social innovation environment. First of all, through the improvement of laws and regulations, and earnestly protect the fruits of enterprise innovation, from the source to prevent infringement, theft of patented technology and other acts; Secondly, the government should promptly give innovative industries a certain degree of government procurement tilt indicators; Finally, continue through the financial, tax and other channels to reduce business costs, thereby reducing R \& D risk, encourage enterprises to achieve profit growth through innovation.

Second, promote regional social capital development level, strengthen the innovation and interaction between enterprises. The social relationship-oriented cultural background makes Chinese enterprises in the intricate social network, which makes our enterprises have greater development space by raising the level of corporate social capital to improve the financing efficiency. Enterprises should pay attention to the construction and consolidation of the credit network with customers and suppliers, and actively strengthen the exchange of senior management between enterprises, as well as business and government and financial institutions, communication and other cooperation between the enterprises to reduce Transaction costs, reduce corporate finance risk, improve the efficiency of corporate finance.

Third, the scientific establishment of senior management team. Senior management team is younger, a strong sense of innovation, education is generally high, which is conducive to the development of enterprise management decision-making is very important. The recruitment of talent and promotion of personnel, the appropriate join the young, highly educated and has extensive experience in the talent to the senior management team to help optimize the team structure, reduce the heterogeneity of senior management team, and the need to gradually upgrade the R\&D department Employees to the management, so that they have the technology on the basis of strengthening the ability of enterprise management, to strengthen the senior management team to do a good job of human resources planning.

\section{References}

1. $\mathrm{Xu}$ Lingling. Institutional environment, ownership structure and technological innovation .Soft Science, 2015 (12): 22-26.

2. Ancona G,Caldwell F. Demography and design:predictors of new product team performance.Organization Science, 1989,3(3):321-341.

3. ZHEN Hong-Xian, ZHANG Xian-Zhi, CHI Gui-Tai.The Impact of Institutional Environment and Ultimate Control on Corporate Performance: An Intermediary Effect Test Based on Agency Cost.Financial Research 2015 (12): 162-177.

4. Williams Y. demography and diversity in organizations: A review of 40 years of research. Research in organizational behavior, 1998, 20 (3): 77-140.

5. Blumberg M, Pringle D. The missing opportunity in organizational Research: some implications for a theory of work performance. Academy of Management Review, 1982, 7 (4): 560-569. 
6. Freel S. Perceived environmental uncertainty and innovation in small firms. Small Business Economics, 2005, 25 (1): 49-64.

7. $\mathrm{Xu}$ Hao, Wen Jun, Feng Tao.Institutional Environment, Financial Development and Technological Innovation.Shanxi University of Finance and Economics, 2016 (6): 44-53.

8. Liu Jibing, Wang Qi, Ma Huanyu. Institutional environment on the strategic emerging industry innovation ability. Science and technology progress and countermeasures 2015 (23): 54-61.

9. Liao Kaorong, Chen Shuangying.Empirical Research on the Impact of Institutional Environment on R \& D Investment of Private Enterprises.Science Research, 2011 (9): 1342-1348.

10. Zhao Huifang, Zhou Yanlei, Zhang Xuan. The Influence of Institutional Environment on Enterprise R \& D Investment. Friends of Accounting, 2011 (31): 31-35.

11. Simons T, Smith K A. Makinguse Of Difference: diversity, debate, and decision comprehensiveness intopmanagementteams. Academic Journal of Management, 1999, 42 (6): 662-673.

12. Zhou Jianhua.Network Relation Embedding, Regional Institutional Environment and Technological Innovation.Journal of Tianjin University of Finance and Economics (in Chinese), 2016 (5): 50-62.

13. Finkelstein S. Top-Management-Team tenure and organizational outcomes: the moderating role of managerial discretion. Administrative Science Quarterly, 1990, 35 (3): 484-503.

14. Allan J D. The effects of reduction in trout density on the invertebrate community of a mountain stream. Ecology, 1982, 63 (5): 1444-1455.

15. ZHANG Biwu, SHI Jintao.Characteristics of Board of Directors, Executive Compensation and Pay Sensitivity: An Empirical Analysis of Chinese Listed Companies .Management Science, 2005 (4): 32-39.

16. SUN Yin-feng, LI Xiao-qing. Heterogeneity, Financial Innovation and Financial Performance of Commercial Banks: Evidence from Listed Banks in Shanghai and Shenzhen.Financial Theory and Practice, 2014 (6): 44-50.

17. Lei Hui, Liu Peng. SME executive team characteristics on the impact of technological innovation - based on the nature of ownership perspective. Journal of Zhongnan University of Economics and Law, 2013 (4): $30-52$.

18. ZHU Jin-wei, PENG Jin-jin, LIU Jing.Study on the Influence of Top Management Team Characteristics on the Input of Technological Innovation in Enterprises - The Regulation Effect of Incentives, Science in Policy, 2014 (8): 17-33

19. Chen Rui, Jing Runtian. The Effect of Team Heterogeneity on Team Members' Innovation Performance. Technology Economics, 2012 (12): 13-21.

20. ZHENG Xiao-Dan, HUANG Yi. Analysis on the Effect of Top Management Team Heterogeneity on the Input of Technology Innovation in Enterprises - An Empirical Analysis Based on Fujian Province and Shandong Province. Journal of Hunan University of Commerce, 2015 (6): 51-57 .

21. BAI Jing-kun, LI Sha-sha. Research on Heterogeneity, Strategic Decision Quality and Innovation Performance of Top Management Teams. Journal of Northeast University of Finance and Economics, 2015 (5): 3-9.

22. XIE Feng-hua, YAO Xian-guo, GU Jia-jun.Empirical Research on the Relationship between Top Management Team Heterogeneity and Firm's Technological Innovation Performance.journal of Scientific Management, 2008,29 (6): 65-73.

23. Putnam M. Bridging network divides: building capacity to support aging with disability populations through research .Disability \& Health Journal, 2014,7 (7): S51-S59. 
24. Zhang Ying. The Impact of Social Capital on Corporate Debt Maturity Structure: Evidence from Listed Companies in China. Journal of Zhejiang Finance and Economics University, 2016 (5): 53-61.

25. Cheng Cong, Xie Hongming, Chen Ying, et al.Study on the Relationship among Network, Internal and External Social Capital and Technological Innovation. Scientific Research Management, 2013 (11): 1-8.

26. Robert A. Ape, o Alessandra Fag, Ian. Cullective learning and relational capital in local innovation processes .regional studies, 2005, 39 (1): 75-87.

27. LIU Yun-guo, LIU Wen.The Term of Office and R \& D Expenditure of Chinese Listed Companies. Management World, 2007 (1): 128-136.

28. Wang Xiaolu, Yu Jingwen, Fan Gang.Analysis of the Indexes of Business Environment in China by Province in 2013 (abstract). Journal of National School of Administration, 2013 (4): 24-34.

29. HOU Wang-bin, ZHANG Yu-li, YANG Jun.Homogeneity or Heterogeneity: The Role of Entrepreneurial Orientation in Regulating the Relationship between Technology Entrepreneurial Teams and New Firm Performance. Management World, 2014 (6): 92-109. 